\title{
LUIS CIFUENTES: UN EJEMPLAR ITINERARIO FORMATIVO, CIENTÍFICO Y PROFESIONAL
}

\author{
Remigio Vela Navarrete.
}

Cátedra y Servicio de Urología. Fundación Jiménez Díaz. Universidad Autónoma Madrid. Madrid. España.

Resumen.- Se describe el itinerario formativo de Luis Cifuentes, en una época en que la urología carecía de prestigio científico y limitado campo de actividad quirúrgica. Su excelente formación en ciencias básicas, su permanente y elegido contacto con los científicos más representativos de la época, su innovadora tesis doctoral y otros iniciativas, junto a su talante inquisidor y extraordinarias dotes personales, le permitieron llegar a la urología con un bagaje excepcionalmente rico en conocimientos.
Con la ayuda de excelentes tutores nacionales e internacionales consiguió una formación urológica de tal calidad que su prestigio científico y profesional fue inmediatamente reconocido, así como su calidad clínica, dominio técnico, rigor investigador. Todo ello le permitió dejar rastro admirable y perdurable. Su itinerario formativo sigue siendo en nuestros días un modelo a seguir por las nuevas generaciones urológicas como complemento del marco oficial del sistema MIR.

Palabras clave: Urología. Biografía. Itinerario formativo. Luis Cifuentes Delatte.

Summary.- We describe the training itinerary of Dr. Luis Cifuentes, in a time in which Urology lacked of scientific prestige and was a limited field of surgery. His excellent education in basic sciences, his permanent voluntary contact with the most representative scientists of that time, his innovative PhD thesis, and other initiatives, altogether with his inquisitorial character and extraordinary personal aptitudes enabled him to get to Urology with an exceptionally rich burden of knowledge.

With the help of excellent national and international mentors he achieved a urological training of such quality that his scientific and professional prestige was immediately recognized, as well as his clinical quality, technical expertise, and research rigor. All these led him to leave an admirable and everlasting trail. His training itinerary continues being a model to be followed by new generations of urologists as a complement to the MIR system.

Keywords: Urology. Biography. Training Itinerary. Dr. Luis Cifuentes Delatte. 


\section{INTRODUCCIÓN}

He elegido para esta presentación * el análisis del itinerario formativo y profesional de Luis $\mathrm{Ci}$ fuentes por su indudable ejemplaridad. Tenemos en este momento al menos 250 urólogos en período de formación en nuestro país, como médicos y residentes de la especialidad de Urología, todos ellos deseando conseguir la excelencia en su formación profesional y muchos de ellos, sin duda, además interesados en seguir una carrera académica e investigadora que necesariamente ha de iniciarse con la imprescindible Tesis Doctoral basada en un proyecto científico que puede marcar de manera extraordinariamente importante su futuro. Desde la titulación de MIR es difícil disponer de la perspectiva integradora necesaria, dentro de la extraordinaria amplitud del quehacer urológico actual, para acertar en la elección temática de ese proyecto que puede ser tan determinante, tanto en el ámbito científico como profesional. Nuestros MIR reclamarán la ayuda de los más próximos, de los miembros del Servicio y del Tutor de residentes y tendrán como alternativa indagar en la historia de la UROLOGIA como disciplina académica y profesional y en las vicisitudes, elecciones y caminos de los grandes urólogos que les han precedido. En este sentido el itinerario formativo y científico de Luis Cifuentes es de ejemplaridad difícilmente superable.

Ciertamente puede aducirse que no es comparable la España de los años treinta del siglo pasado con la actual, en tantos aspectos que cualquier análisis simultáneo y comparativo quedaría invalidado. Sin embargo, aunque las diferencias sociales y económicas sean completamente distintas, los fundamentos y motivos para la elección de un proyecto científico y profesional no son tan distantes; de hecho continúan siendo los mismos. Este será precisamente el objetivo que pretendemos demostrar en los comentarios que siguen, que ahora tienen mayor relevancia cuando el futuro de la Urología, siempre cambiante, es sometido a múltiples análisis todos los cuales coinciden en que durante los próximos años vamos a ver modificaciones muy importantes de nuestra especialidad y profesión.

\section{Itinerario formativo: la urología y los urólogos de los años treinta.}

La definición de Urología desde su conformación como especialidad y disciplina no ha cambiado; tanto entonces como ahora la Urología sigue

\footnotetext{
* Mesa Redonda homenaje al Dr. Luis Cifuentes. Alicante 1-Febrero-2007
}

siendo la especialidad que se ocupa del diagnóstico, tratamiento y prevención de las enfermedades del aparato urinario, en ambos sexos, y del aparato reproductor en el varón. Si la declaración de intenciones no ha cambiado en más de 100 años lo que sí ha cambiado y sigue cambiando, y de manera muy acelerada en las últimas décadas, es el contenido de la Urología y la imagen profesional del urólogo y su posición en el Sistema Sanitario de los diferentes países, con variado prestigio y relevancia social.

En los años treinta del pasado siglo, incluso hasta los 50, la Urología era una especialidad enormemente humilde y de muy escaso prestigio científico. Joseph Kaufman hizo famosa la frase siguiente: empezamos como médicos de gonorreas y terminaremos como médicos de gonorreas (We started out as clap doctors and we will end as clap doctors). Efectivamente una parte importante del trabajo urológico estaba dedicado al cuidado del uretra. Las tres referencias siguientes pueden aproximarnos al ambiente en que se movían desde el punto de vista profesional los urólogos de aquella época. En el museo Thyssen-Bornemisza de Madrid está el cuadro del doctor Haustein (Figura 1) pintado por Christian Schad en 1928 en el que aparece el doctor sentado, de frente, con las manos cruzadas, mirando al pintor, y con un BENIQUÉ asomando del bolsillo de la chaqueta. Aunque él BENIQUÉ, el instrumento más común para el cuidado de la uretra, era casi el símbolo de la urología de la época, el doctor Stein no era urólogo sino dermatólogo. Tengo en mi biblioteca un interesante libro publicado conjuntamente por Pedro Cifuentes y E. A. Sainz de Aja (Jefe de Servicio de Dermosifilografía del Hospital de San Juan de Dios), en Madrid, el año 1927, por Javier Moráta, ed. con el siguiente título: "Prácticas de urología y sifilografía" (Figura 2). Naturalmente todo el libro está dedicado al cuidado de la uretra. Este compromiso persiste al menos durante dos décadas más; el libro del profesor R. Alcalá Santaella, también editado por Morata en 1942, con el título de "Urología Clínica" (Figura 3) está todavía dedicado en su mayor parte a los problemas relacionados con las infecciones uretrales. Naturalmente había otros muchos temas que ocupaban el interés de los urólogos de la época pero de forma más especializada y minoritaria; la cirugía prostática, la gran aventura científica emergente de la época, y por supuesto, la tuberculosis genitourinaria es otro motivo de cuidadosa atención junto con su tradicional interés por la litiasis en sus muy variadas formas de presentación incluida la litiasis vesical, de no despreciable frecuencia.

Dominar la litotricia ciega era todo un reto para aquellos urólogos. Los riesgos, sobre todo los sépticos, con infecciones fulminantes eran muy fre- 


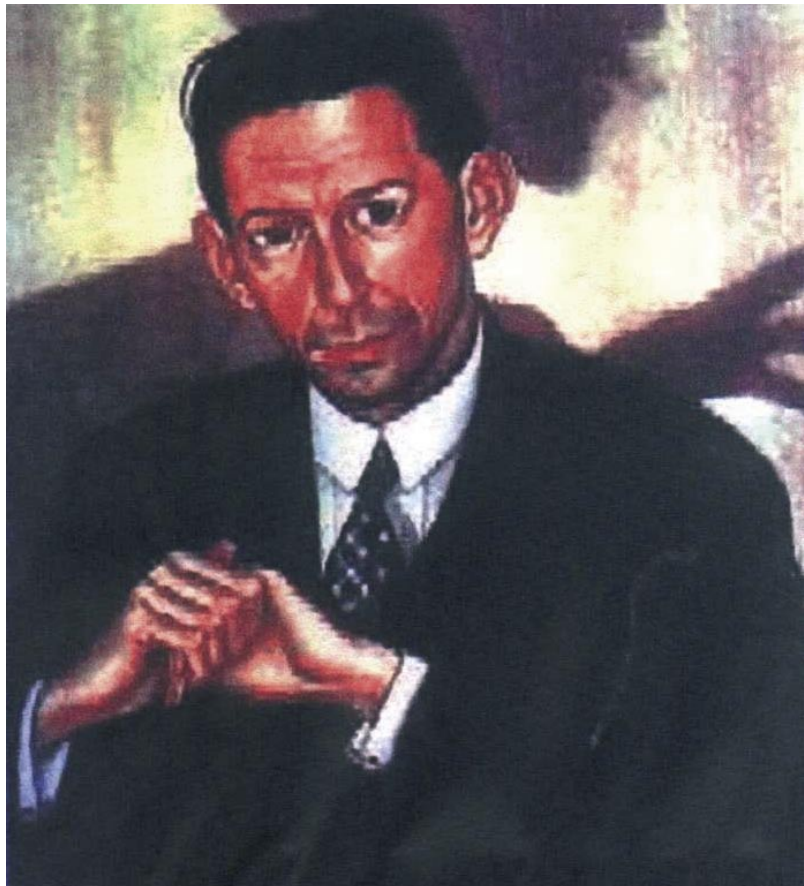

FIGURA 1. El Dr. Haustein era Dermatólogo.

cuentes y sus consecuencias trágicas. Cuentan de Hartelup, un urólogo parisino conocido por su pericia en la litotricia ciega pero un tanto pretencioso, que un día presumiendo de su ultima proeza, afirmó: El paciente que operé esta mañana está ahora paseándose por los Campos Elíseos, afirmación a la que alguien de la audiencia añadió la siguiente in- terrogante; ¿̇los Campos Elíseos de Paris o los del cielo?

\section{PROGRESOS CIENTÍFICOS Y PROFESIONALES EN LOS AÑOS 40}

Además de la patología uretral infecciosa la práctica urológica de los años treinta estaba definitivamente comprometida con el diagnóstico y tratamiento de la tuberculosis genitourinaria en toda Europa. Los TISIOLOGOS, (hoy día inexistentes, ocupaban un puesto destacado en el sistema sanitario. Los urólogos atendían estos pacientes en la era preantibiótica con estrategias curativas a veces aterradoras en sus consecuencias, como la famosa "nefrectomía d'amblé". Esta intervención se realizaba después de localizar la bacteriuria, en este caso la baciluría, mediante el cateterismo ureteral para cuya realización Albarrán había inventado su famosa uña o elevador. La pandemia de tuberculosis en Europa estimuló dos grandes avances urológicos; el desarrollo y consecución de los procedimientos radiográficos que permitieron visualizar el aparato urinario superior, primero con la pielografía ascendente en 1914 por Volker y luego mediante la urografía intravenosa que no llegó hasta los años 30 de la mano de MOSES SWICK y VON LICHTENBERG. LA introducción del uroselectan en España, como han relatado Jiménez Garrido y Sánchez de Badajoz, curiosamente tuvo mucho que ver con la dinastía de nuestros profesores de Patología Quirúrgica los Vara-Thorbeck. Por otro lado, la investigación microbiológica de laboratorio, ya que

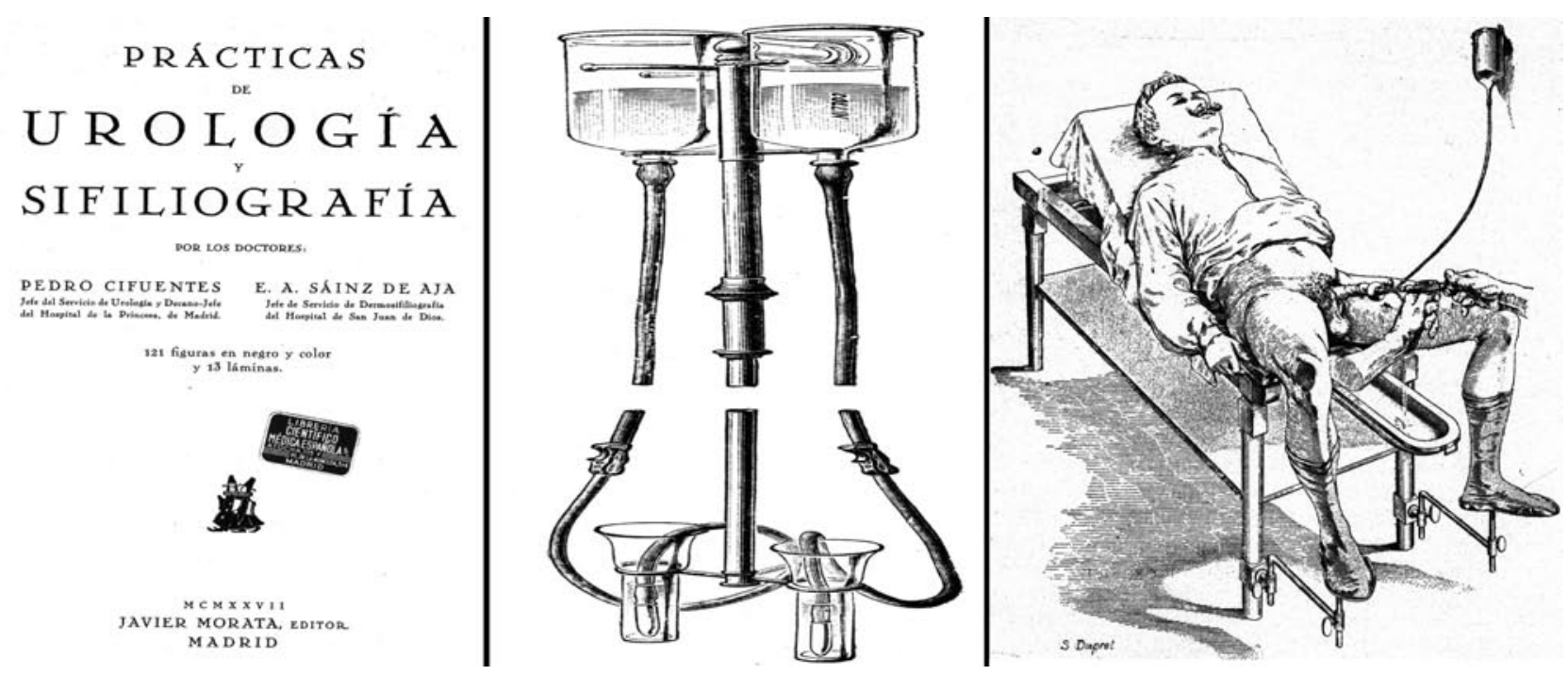

FIGURA 2. Libro publicado conjuntamente por Pedro Cifuentes y E.A. Sainz de Aja Ulefe de servicio de Dermosifilografia del Hospital de San Juan de Dios), en Madrid, el año 1927, por Javier Moráta, ed.

"Prácticas de urología y sifilografía y técnica del lavado uretral, tan común en aquella época" 
PROF. R. ALCALÁ SANTAELLA CATEDRATICO DE LA FACULTAD DE MEDICINA DE VALENCIA Y
JEFE DEL. SERVICIO DE UROLOGIA DEE HOSPITAL PROVINCIAL.

\section{UROLOGÍA C L I N I C A DE LOS TRASTORNOS DE LA SECRECIÓN URINARIA Y DE LA MICCION \\ TOMO PRIMERO PRIMERA PARTE CON 27 FIGURAS PRIMER A
EDICION

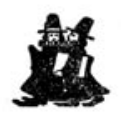 MCMXLII EDICIONES MORATA BARCELONA MADRID \\ BUENOS AIRES}

FIGURA 3. Libro del profesor R. Alcalá Santaella, también editado por Morata en 1942. "Urología Clínica"

era precisamente en la consulta del urólogo donde se hacía la baciloscopia moderna consistente no sólo en mirar el sedimento urinario si no indagar sobre la presencia de bacterias en la orina y muy especialmente aplicando técnicas como la de Zhiel-Nielsen para la detección del bacilo tuberculoso.

La otra gran protagonista de la práctica urológica, en este caso en el quirófano del Hospital, era la cirugía prostática. En el VIII Congreso de la Asociación Española de Urología y I Hispanoportugués, en Madrid 2-4 Mayo 1928, presidido por D. Leonardo de la Peña, precisamente el tema fundamental se refirió a "Técnicas y resultados de la prostatectomía", presentado por el Dr. Benigno Oreja Elosegui, de San Sebastián, aparentemente uno de los primeros en realizar este tipo de cirugía en España. La litotricia vesical era, como señalado, un procedimiento reservado a grandes expertos, por sus enormes riesgos, y la cirugía de la litiasis y la reconstructiva en la tuberculosis, apenas existente.

Esta era pues la urología de finales de los años treinta en nuestro país, no especialmente brillante ni en el aspecto científico ni profesional. La urología de la época iba poco a poco progresando y consolidándose, aún sin independencia académica ni universitaria, siendo una mínima sección de los Departamentos de Cirugía. El Dr. Pulido (Figura 4), años después, recordaba lo siguiente sobre el nivel académico y profesional de los urólogos: "Los cirujanos consideraban a los urólogos un algo despectivamente; les creían todavía en la edad de los antiguos curanderos que recorrían España sacando las piedras en las plazas de los pueblos. Ya hacían bastante con dejarle el tramo urinario inferior, la uretra y algo de la vejiga". Pero ya se advertían signos que precedían al progreso.

Esta era la urología que practicaba Pedro Cifuentes que había terminado la carrera en 1904 y sus coetáneos entre los que es preciso recordar a Leonardo de la Peña, el primer Catedrático de Urología de la Universidad Central, Salvador Gil Vernet, Alcalá Santaella, Mariano Serés y otros muchos como González Bravo, Negrete, etc.

Sánchez de Badajoz ha calificado a esta generación de urólogos, a los que hay que añadir además de los mencionados, Jose María Batrina Tho-

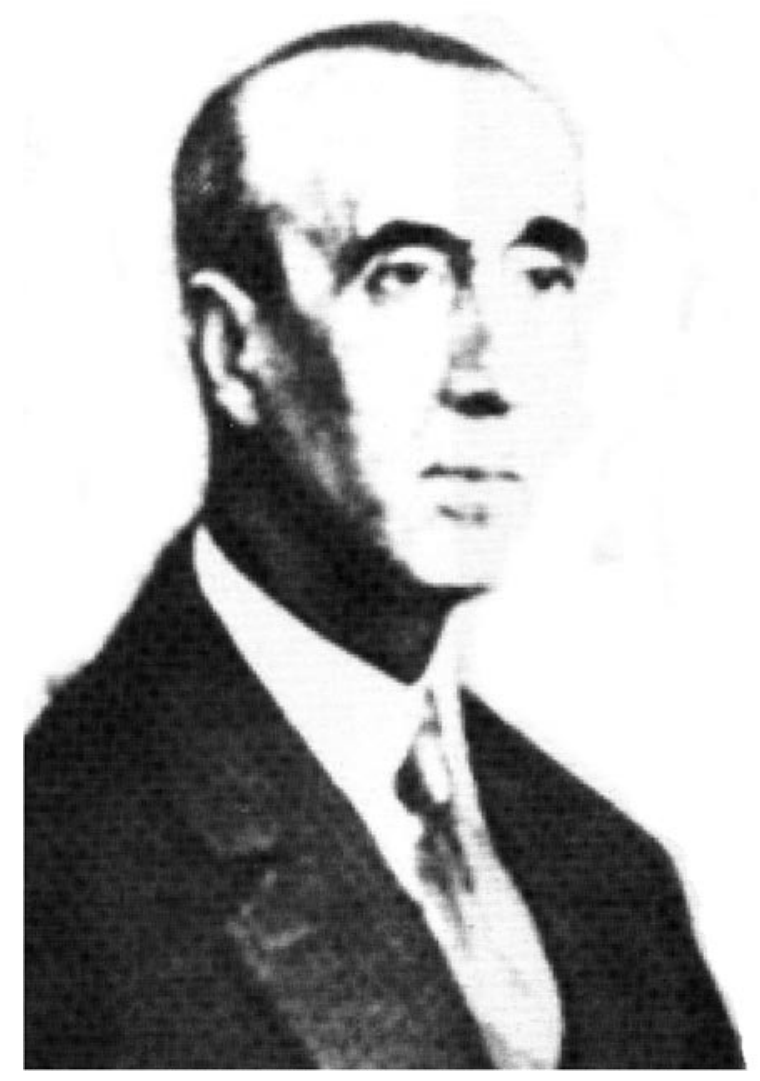

FIGURA 4. El Dr. Pulido. 
más (Figura 5), Angel Pulido Martín, Isidro Sánchez Covisa (Figura 6), Narciso Serrallach Mauri, Manuel Villar Iglesias, y otros, la Generación del 98. No es éste el momento de exponer los motivos por los que muchos de nuestros urólogo de los años 40 estaban tan próximos a la Anatomía de tal modo que algunos de ellos eran Profesores ó Catedráticos de Anatomía, pero no de Patología Quirúrgica, salvo el muy excelso José María Batrina Thomas.

\section{LUIS CIFUENTES Y LA PASIÓN POR EL CONOCIMIEN- TO DE CARLOS JIMÉNEZ DÍAZ}

Desde esta perspectiva de la urología española de los años 30-40 podemos entender las dudas de Luis Cifuentes para continuar la tradición familiar urológica. En primer lugar hay que destacar que no se sentía en absoluto atraído por la urología. Carlos Jiménez Díaz había llegado a Madrid desde Sevilla, en 1924, y Luis Cifuentes fue alumno suyo de Patología Médica, convirtiéndose en uno de sus discípulos más entusiasta y finalmente, predilecto. Luis Cifuentes se sintió, como ha confesado en muchas ocasiones, inmediatamente atraído por la pasión por el conocimiento de Carlos Jiménez Díaz (Figura 7), convirtiéndose en uno de sus alumnos más próximos

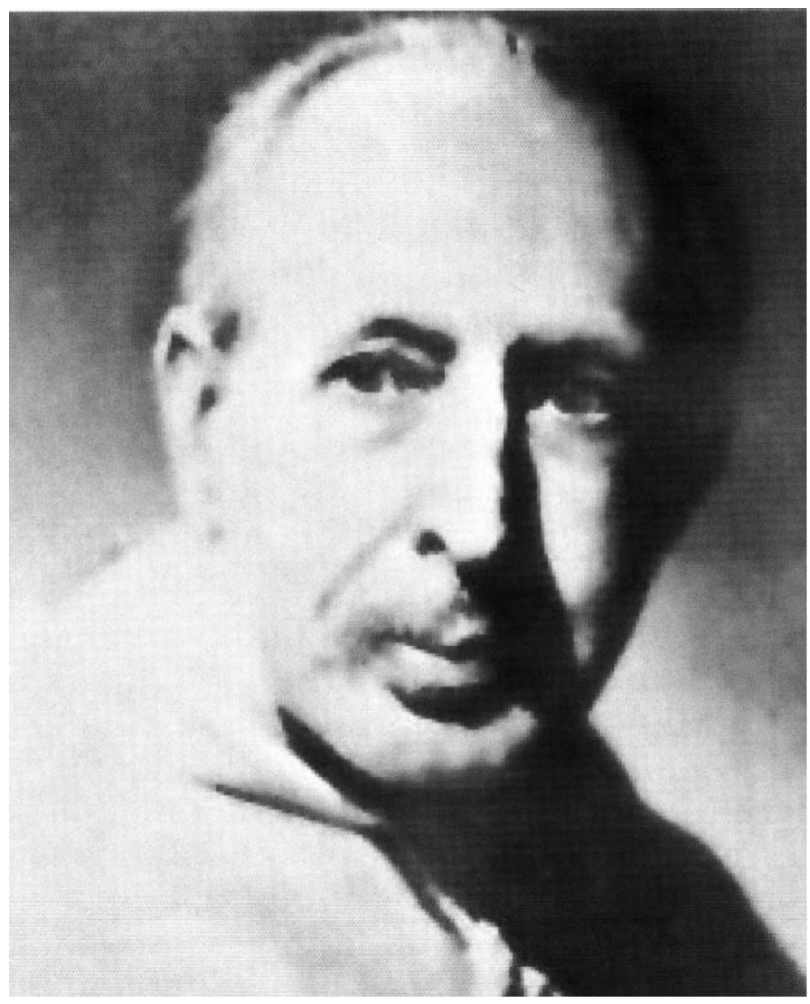

FIGURA 5. José María Batrina Thomas. y entrañables. A su vez, Carlos Jiménez Díaz le distinguió siempre con el mayor afecto y admiración por su trabajo. Bajo su dirección inició su Tesis Doctoral sobre "El equilibrio hidroelectrolítico". Era tan novedoso el tema que a los interesados les llamaban los de los "iones" y fueron acusados de esnobismo y quizás, pedantería. Adelantemos ya que la química que aprendió Luis Cifuentes durante la realización de su Tesis Doctoral fue extraordinariamente importante y decisiva en mucho de los trabajos que acometió en los años siguientes, tanto en temas específicamente urológicos, como la litiasis o la alcalinización de la orina, las investigaciones sobre los fosfatos apatíticos, etc., como en temas relacionados con la nefrología clínica cuyo origen se situó precisamente en su época más productiva: ¿Qué diferencia existe entre $\mathrm{Ph}$ y acidez titulable?, solía preguntar a los que iniciaban la nefrología, tan próxima al laboratorio en aquellos momentos, para continuar ilustrándolos con extraordinaria claridad en temas que aparecían enormemente complejos y difíciles.

También influyó en su itinerario científico la elemental técnica de laboratorio que se realizaba en la consulta de su padre. Ello le permitió acercarse con experiencia y conocimiento a aquéllos primeros estudios sobre la infección urinaria realizados con

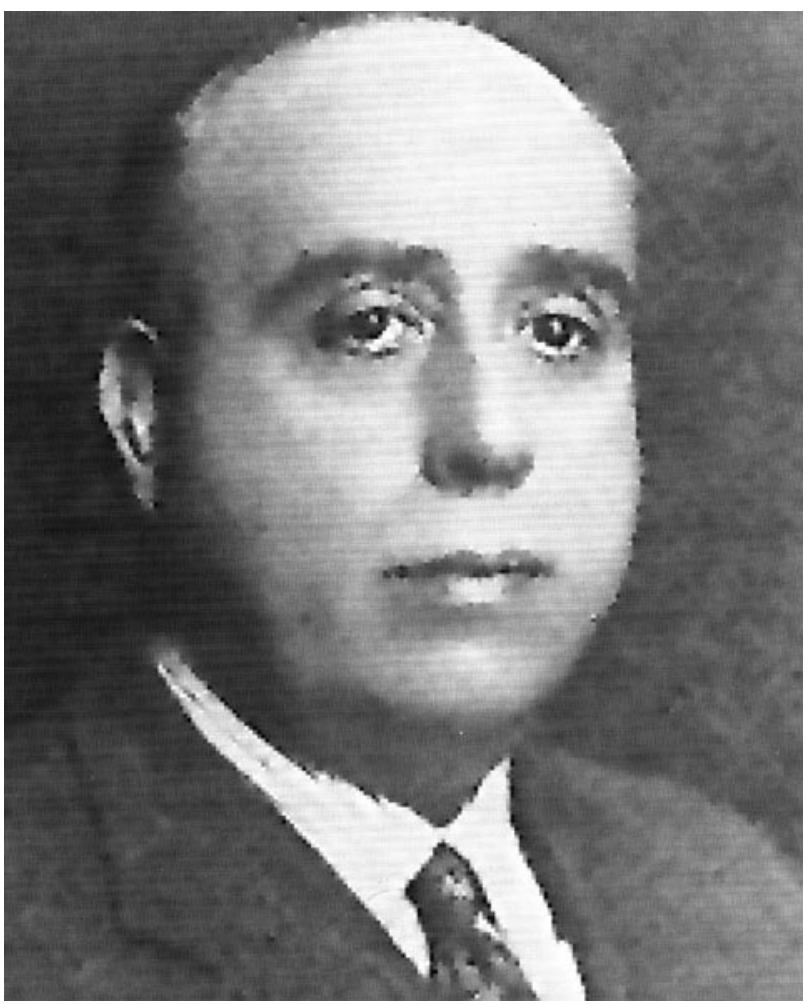

FIGURA 6. Isidro Sánchez Covisa. 


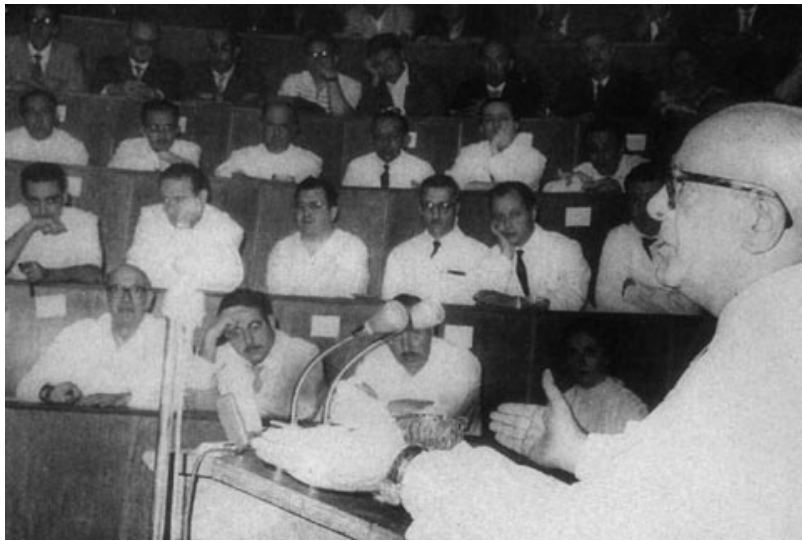

FIGURA 7. Carlos Jiménez Díaz.

Gonzalo Urgoiti y Ramón Urioste, en los que ya su perspicacia investigadora le permitió, no sólo describir unos hallazgos, como solemos hacer, en su caso con un excelente castellano, sino intuir que una bacteria que pasaba aparentemente desapercibida entre los patógenos urinarios podría tener notable trascendencia, iniciando de este modo la larga historia del descubrimiento del Corynebacterium Urealiticum. Hemos relatado esta historia en un trabajo titulado: "Historia de un descubrimiento anunciado" y siempre hemos propuesto este proceso investigador como modelo del rigor científico que animaba a Luis Cifuentes.

El microscopio formaba parte del equipamiento habitual del urólogo en aquellos tiempos, pero no sólo para mirar las orinas o el exudado uretral o la secreción prostática, si no para indagar algunos aspectos histológicos de interés. Los alumnos de Ramón y Cajal, además de compartir con orgullo su Premio Nobel, concedido el año 1906, hacían uso frecuente del microscopio para confirmar sus diagnósticos de fundamento anatomoclínico. Era el gran momento de la medicina anatomoclínica; una lesión y un síndrome clínico.

Gonzalo Rodríguez Lafora describió precisamente en los años 30 el corpúsculo que fundamentó la enfermedad que lleva su nombre y estos hallazgos estimulaban a sus coetáneos de una manera especial. Luis Cifuentes aprendió histología y patología y no de manera superficial, si no en profundidad, con criterios. Ello le permitió llegar a la literatura mundial con una de sus primeras publicaciones en el J. Urol. sobre el "Epitelio de tipo vaginal en la vejiga urinaria". Pero más importante, se dio cuenta que esta descripción anatomoclínica tenía un enorme vacío en relación con las cistitis y cistopatías. Valiéndose de la endoscopia, que ya dominaba, y de un cuidadoso acercamiento clínico a los pacientes inició un trabajo que finalmente encontraría su síntesis en la primera publicación de "Cistitis y Cistopatías", editado por Paz Montalvo en Madrid en 1947 (Figura 8).

En definitiva Luis Cifuentes se encuentra mucho más atraído por la investigación y por la pasión por el conocimiento científico de Carlos Jiménez Díaz que por ningún otro motivo especial. Del ambiente familiar toma iniciativas próximas al laboratorio y de la información que de él puede conseguirse. Finalmente, cuando preocupados en el ambiente familiar por su desinterés por la Urología su madre le hace la famosa pregunta que cambió su itinerario científico (Luis; $\dot{\partial}^{E s}$ que no hay nada que investigar en urología?) y decide ser urólogo, alcanza el comienzo de la especialidad con un bagaje científico extraordinario que marcará definitivamente su trayectoria profesional.

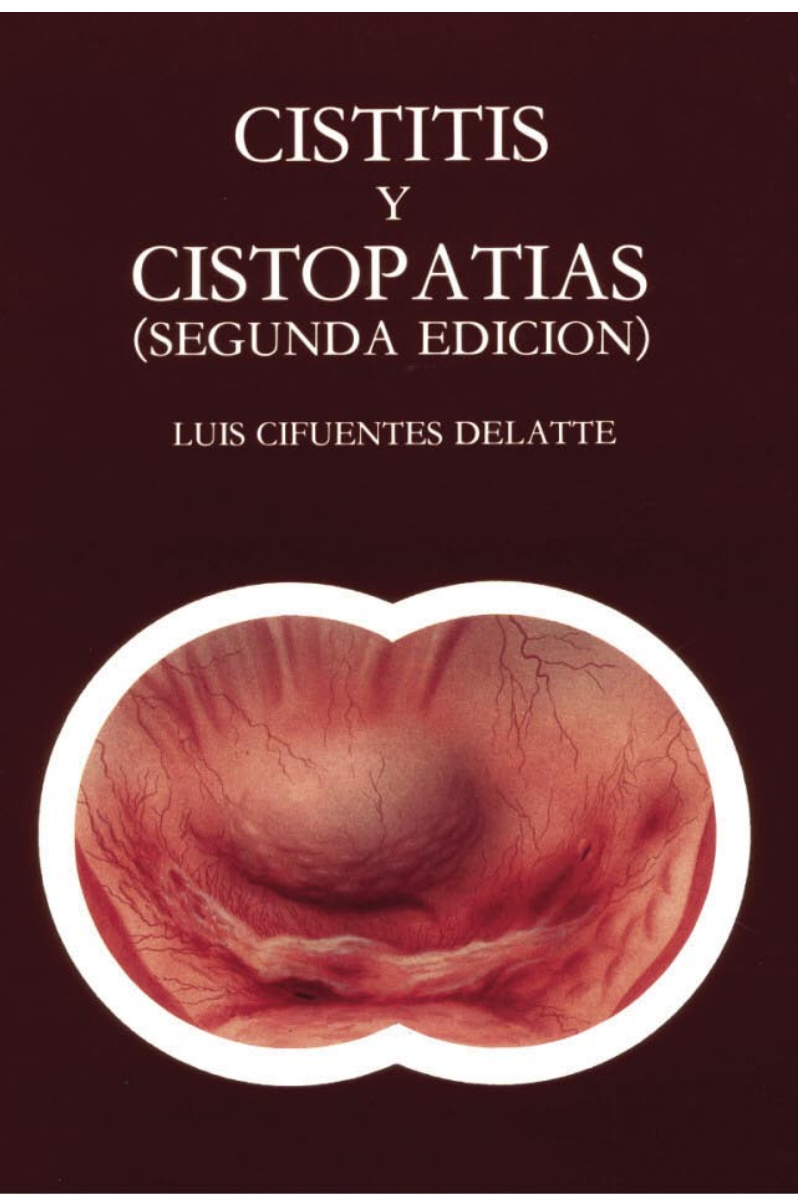

FIGURA 8. "Cistitis y Cistopatías", editado por Paz Montalvo en Madrid en 1947. En la imagen la portada de la segunda edición (BOK Ediciones 1989). 


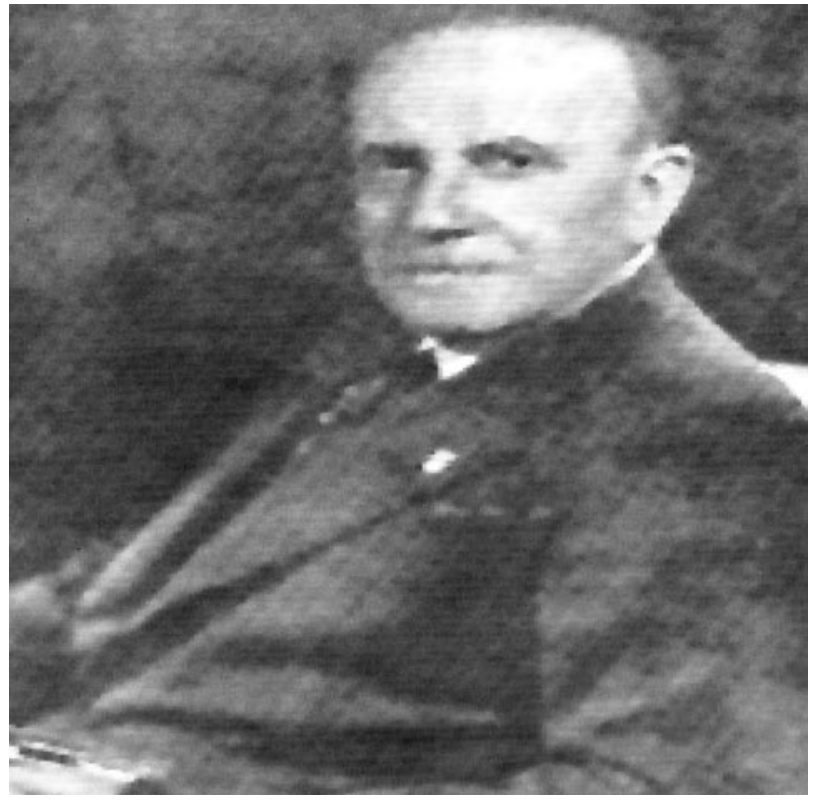

FIGURA 9. Pedro Cifuentes.

Decidida la formación urológica y manteniendo siempre el contacto con Jiménez Díaz, inicia su formación quirúrgica general con Plácido González Duarte en el Hospital de la Princesa, la urológica con su padre Pedro Cifuentes (Figura 9), Jefe del Servicio de Urología del Hospital de la Princesa, al mismo tiempo que mantiene contactos con amigos y compañeros interesados por la microbiología, importantísima en la urología de la época, así como la histología y anatomía patológica. No se entiende una formación completa en la especialidad urológica, sin una salida al extranjero donde comparar lo conocido con nuevas estrategias e iniciativas. Su padre había sido alumno de Albarrán y él hablaba francés con la misma soltura que español. Pero también alemán, y el prestigio internacional del Servicio de Urología de Von Lichtenberg en Berlín no escapa a sus noticias y es donde completa su formación durante los años 1930 a 1932.

Su inquietud no se reduce exclusivamente a las técnicas operatorias urológicas, sino que continúa interesado por la histología, la microbiología y las ciencias básicas y cuando Von Moellendorf describe la histología vesical, la que a su juicio es la mejor descripción histológica de la vejiga urinaria, en 1930, en Friburgo, allí está Luis Cifuentes a ver sus preparaciones y comentar con él sus dudas y sus hallazgos. Años más tarde completaría su formación quirúrgica en la técnica más avanzada de la épo$\mathrm{ca}$, la resección transuretral, viajando a Ann Arbor donde Red Nesbit había alcanzado merecida fama internacional por sus conocimientos y perfección de esta técnica quirúrgica.

\section{CONCLUSIONES}

Hemos señalado en este itinerario científico de Luis Cifuentes que la clave de su extraordinaria proyección nacional e internacional en investigaciones tan variadas como microbiología, cristalografía, histología, litogénesis, morfogénesis prostática, etc., se fundamentó en una extraordinaria y profunda preparación en ciencias básicas. Solía decir que no somos sólo "litotomistas", le molestaba profundamente el que algunos colegas redujesen la extraordinaria amplitud del conocimiento urológico a un reducido título en su tarjeta de visita, cirujano urólogo, e insistía en la invalidez de una estrategia basada en "cocerse en su propia salsa".

Por el contrario, mantuvo siempre, a pesar del agobio asistencial, contactos variados con expertos en campos tan distintos como la microbiología, la bioquímica, la cristalografía o edafología, la histología, etc. Sólo los que dominan en profundidad estos temas apreciaban los extraordinarios conocimientos de Luis Cifuentes en cada uno de ellos. No es extraño que B. Finlayson, Profesor de la Universidad de Florida en Gainesville, afirmará de el lo siguiente: "Lo que van a escuchar ustedes sobre Cristalografía litiásica es sólo posible en un hombre exclusivamente dedicado al estudio de este tema. Sin embargo, el Prof. Cifuentes es un urólogo práctico con un compromiso asistencial extraordinario, que ha encontrado tiempo y pasión para realizar este insuperable trabajo de investigación". Efectivamente, Luis Cifuentes publicaba en Science o Nature sus trabajos científicos, elevando, de este modo y de otras muchas maneras, el nivel científico de la urología española a alturas y cotas hasta entonces no alcanzadas.

Ahora, en el momento en que en todas partes del mundo la urología habla demasiado de "procedimientos" y "objetivos de gestión" y olvida al enfermo y a la enfermedad, con las consecuencias nefastas que puede tener esta imposición de torcida política sanitaria, ya que a juicio de los expertos por este camino perderemos no sólo el procedimiento sino los enfermos, el ejemplar itinerario formativo, científico y profesional de Luis Cifuentes es más que nunca el modelo a seguir e imitar. No solo conseguirán los nuevos urólogos satisfacciones personales en este renovado itinerario de medicina humanizada e inexcusablemente científica si no que preservaran la extraordinaria carga asistencial que el incremento de la longevidad poblacional augura con certeza. 